\title{
Scopolamine does not reduce tonic immobility in chickens
}

\author{
CHARLES KSIR \\ University of Wyoming, Laramie, Wyoming 82070
}

\begin{abstract}
Chickens that were given up to $1.0 \mathrm{mg} / \mathrm{kg}$ scopolamine hydrobromide $15 \mathrm{~min}$ before testing did not show a reduced duration of tonic immobility when a 15 -sec restraint procedure was used to induce immobility. Chickens given $2.0 \mathrm{mg} / \mathrm{kg}$ scopolamine did not show decreased duration or probability of induction of tonic immobility compared to chickens injected with physiological saline. These results contradict those of a previous study.
\end{abstract}

Thompson, Piroch, Fallen, and Hatton (1974) have reported that scopolamine, a competitive inhibitor of acetylcholine receptors, decreased the duration of the tonic immobility (TI) reflex, a phenomenon in which animals that are initially restrained remain immobile after restraint has been discontinued. Their experiment employed young (12-19-day-old) chickens. Thompson et al. (1974) suggest that TI is mediated by a central nervous system cholinergic pathway, since, in their experiment, methylscopolamine, which does not readily enter the brain but has similar effects to scopolamine in the peripheral nervous tissues, did not increase TI. However, results from our laboratory do not agree with the finding that scopolamine decreases TI. While failures to find significant drug effects are not usually of much interest, in this case it is possible to show that the current results are importantly different from those, obtained by Thompson et al., and to propose an alternative explanation of their results. Since their published result has recently been included in a review stressing the value of TI studies for neuropharmacological analyses (Klemm, 1976), it seems important to clarify the issue at this time.

\section{EXPERIMENT 1}

Having heard of the Thompson et al. (1974) results prior to their publication, an attempt to use the phenomenon as a laboratory demonstration had failed. Experiment 1 was an attempt to replicate as nearly as possible the Thompson et al. experiment, using fewer doses. The earlier experiment had used doses as high as $2.5 \mathrm{mg} / \mathrm{kg}$ scopolamine, but the most dynamic portion of the dose-effect curve was from 0.25 to $1.0 \mathrm{mg} / \mathrm{kg}$, with a maximal effect found at $1.5 \mathrm{mg} / \mathrm{kg}$. The current experiment examined the effects of $0.25,0.50$, and $1.0 \mathrm{mg} / \mathrm{kg}$ scopolamine hydrobromide, and of $1.0 \mathrm{mg} / \mathrm{kg}$ methylscopolamine bromide.

\section{Method}

Subjects. Mixed breed and sex chickens were obtained from the University of Wyoming poultry farm on the day of their hatching and were placed in heated brooding pens for the next 14 days with free access to food and water. Sixty chickens were employed in Experiment 1, with all testing done when chickens were 14 days of age.

Apparatus and Procedure. Each chicken was removed from the brooding pen, weighed, and then injected intraperitoneally with either physiological saline or $0.25,0.50$, or $1.0 \mathrm{mg} / \mathrm{kg}$ scopolamine hydrobromide or $1.0 \mathrm{mg} / \mathrm{kg}$ methylscopolamine bromide (salt weights) in a volume of $1 \mathrm{ml} / \mathrm{kg}$ body weight. Injections were given by the author according to a sequence which was randomized, but balanced so that five chickens in each dosage group would be restrained by the left hand and the other five restrained by the right hand. Two chickens were injected every $5 \mathrm{~min}$, and immediately after injection each chicken was placed in a $15-\mathrm{cm}$-diam coffee can. After each pair of chickens had been in the holding cans for $15 \mathrm{~min}$, they were removed by a student volunteer who had no knowledge of the dosage schedule. One chicken was held in each hand for $15 \mathrm{sec}$, then they were placed on a table, separated from each other by a vertical $30 \times 46 \mathrm{~cm}$ gray board, and held on their sides for $15 \mathrm{sec}$. The student then timed the duration of the TI response until the bird stood on its feet or until a maximum of $180 \mathrm{sec}$ had elapsed. Each bird was tested only once.

\section{Results and Discussion}

Figure 1 shows the mean duration of TI for all five groups. The standard error of each mean is given by the bars above and below each point. An analysis of variace on all these data (the same type of analysis done by Thompson et al.) found no significant differences among the groups $[F(4,55)=$ 1.63]. Although the data are quite variable, as is to be expected of latency data, the failure to find significant differences between groups reflects the fact that the group means do not change greatly. In the Thompson et al. study, the means for saline, methylscopolamine, and $0.25 \mathrm{mg} / \mathrm{kg}$ scopolamine (none of which were reported to be different from the others) were about 175, 136, and $139 \mathrm{sec}$ (estimated from their Figure 2, p. 510). However, their mean duration for the $0.50-\mathrm{mg} / \mathrm{kg}$ group was about $104 \mathrm{sec}$, and for the $1.0 \mathrm{mg} / \mathrm{kg}$ group about $60 \mathrm{sec}$. In the 


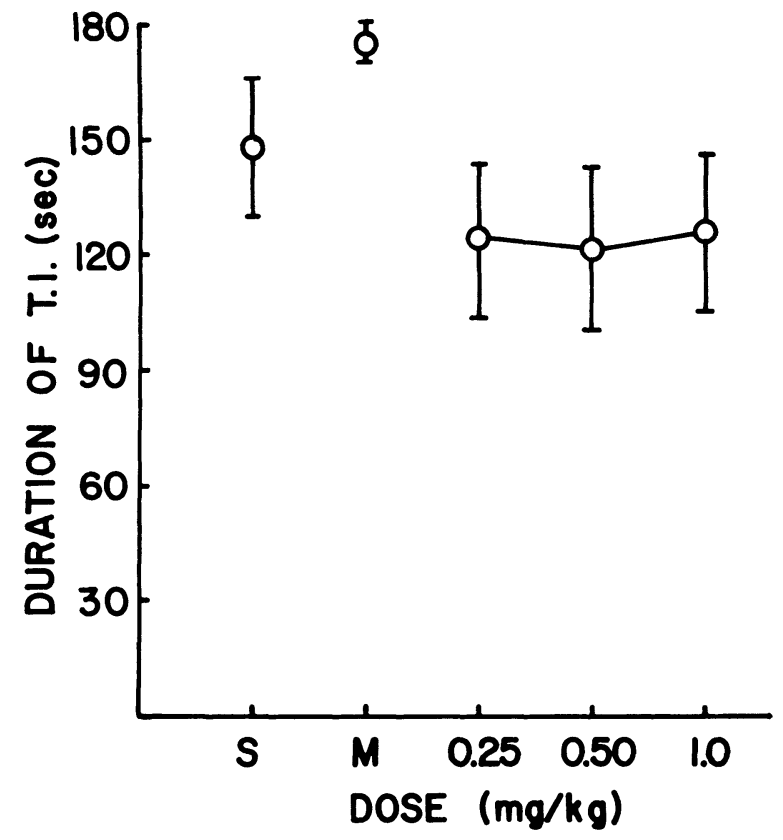

Figure 1. Effects of scopolamine and methylscopolamine on the duration of tonic immobility. Each point represents the mean duration for 12 chickens, and the bars above and below the points represent the standard error of the mean. S: saline controls; M: $1.0 \mathrm{mg} / \mathrm{kg}$ methylscopolamine.

current experiment, there is no evidence for such a drastic reduction in TI duration at these doses. Since testing on these chickens was done in three sessions, 1 week apart, and since fresh drug solution was mixed prior to each test session, it is unlikely that an ineffective solution was responsible for the lack of results.

\section{EXPERIMENT 2}

The great variability in the data of Experiment 1 reflects the fact that, with the 15 -sec restraint procedure, a large proportion of the chickens remain in TI past the 180 -sec cutoff, and a number of other chickens right themselves in a few seconds, indicating that they may not have actually been in the TI state. The Thompson et al. data could have resulted either from a shortening of the TI state, once induced, or from a decreased probability of induction of TI after scopolamine. Small differences in the restraint procedure between their experiments and our Experiment 1 could, therefore, possibly have accounted for the different effects of scopolamine. In Experiment 2, the effects of a larger dose of scopolamine $(2.0 \mathrm{mg} / \mathrm{kg})$ were tested using two measures: the duration once TI had successfully been induced, and the probability of TI induction using a standard restraint procedure.

\section{Method}

Chickens were obtained and housed as before, and all were tested at 14 days of age. The injection procedure was as before, except that in each pair of birds one was injected with saline and the other with $2.0 \mathrm{mg} / \mathrm{kg}$ scopolamine hydrobromide. The sequence was again randomly determined, with the restriction that half of each group would be restrained with the left hand and half with the right hand. Again, the student volunteer who restrained the animals and recorded the times was unaware of the injection schedule. Twenty chickens were tested, 10 in each group. On the first test,each chicken was restrained as before, but if the latency to righting was less than $10 \mathrm{sec}$, the chick was restrained again. The student was instructed to restrain the chickens "until they were ready," not for a specific amount of time. Following the first test, each chicken was immediately tested four times in succession, using a 10-sec hold, 10-sec restraint procedure. In these four tests, the only measure taken was whether or not the chicken remained on its side for $10 \mathrm{sec}$ or longer.

\section{Results and Discussion}

In the first test, it was possible to induce TI in all chickens, although some required two or three attempts. Once each chicken had remained down for $10 \mathrm{sec}$, all 20 of them remained down for the $180 \mathrm{sec}$ allowed. Thus there was no difference, using this procedure, in the duration of TI, once induced, between chickens injected with saline and chickens injected with $2.0 \mathrm{mg} / \mathrm{kg}$ scopolamine. On the second measure, the number of times out of four attempts that each chicken remained off its feet for $10 \mathrm{sec}$ or longer,the mean for the saline group was 2.7 and the mean for the $2.0-\mathrm{mg} / \mathrm{kg}$ scopolamine group was 2.8 , an almost identical result.

In the Thompson et al. study, the mean duration of TI was only $30 \mathrm{sec}$ for the $2.0 \mathrm{mg} / \mathrm{kg}$ scopolamine group, but the current data indicate that there is no effect of this dose of scopolamine on the probability of induction or on the duration of TI, once induced, at least up to $180 \mathrm{sec}$. The current results also argue against using a 180 -sec cutoff, since once TI is successfully induced it frequently lasts much longer than that. Recent data from the Tulane laboratories, where a repeated induction procedure is used, indicate that average control groups may have durations of $500-600 \mathrm{sec}$ (Maser, Gallup, \& Hicks, 1975; Maser, Gallup, Hicks, \& Edson, 1974).

\section{EXPERIMENT 3}

In order to assess the effectiveness of these scopolamine injections in these chickens, the drug's effect on locomotor activity was studied. Thompson et al. had reported significant changes in open-field activity with scopolamine.

\section{Method}

Chickens were obtained and housed as before, and all were tested at 14 days of age. Two $18 \times 18 \times 25 \mathrm{~cm}$ galvanized wire cages were modified with a lamp and photocell so that the light beam bisected the cage along its long axis, $2.5 \mathrm{~cm}$ above the cage floor. Each interruption of the light beam was counted and the counts printed out every 15 min (Coulbourn Model R21-16 electronic printing counter).

A pair of chicks was randomly selected, each was injected 
according to the previously established schedule, and they were placed in the test cages for $1 \mathrm{~h}$. The injection schedule allowed for the presentation of the doses in a mixed order, with the constraint that two chickens given each dose were tested in each cage. There were thus four chickens in each of the three drug conditions: saline, $0.5 \mathrm{mg} / \mathrm{kg}$ scopolamine, and $1.0 \mathrm{mg} / \mathrm{kg}$ scopolamine.

\section{Results and Discussion}

Figure 2 presents the mean number of beambreaks per 15-min period for each of the three dosage groups. An analysis of variance for repeated measures found no overall significant time or dose effect, but a significant Dose by Time interaction $[F(6,27)=2.52, p<.05]$. This reflects the fact that the activity effect was largest in the early portion of the test hour.

These results demonstrate that scopolamine does have behavioral effects in this type and age of chicken, at a dose of $1 \mathrm{mg} / \mathrm{kg}$, within a few minutes after injection. The scopolamine used in this experiment was mixed from the same bottle of powder as in the previous experiments.

\section{GENERAL DISCUSSION}

However inadequate the procedures used in the current experiments and in the Thompson et al. (1974) experiments, the current results argue against their finding that scopolamine reduced the duration of TI.

Our results are in agreement with those of Master et al. (1975), who found that atropine, which is functionally similar to scopolamine, had no effect on TI duration. Recently, Woodruff, Hatton, Frankl, and Meyer (1976) reported that scopolamine reduced TI duration in ducks but increased TI duration in

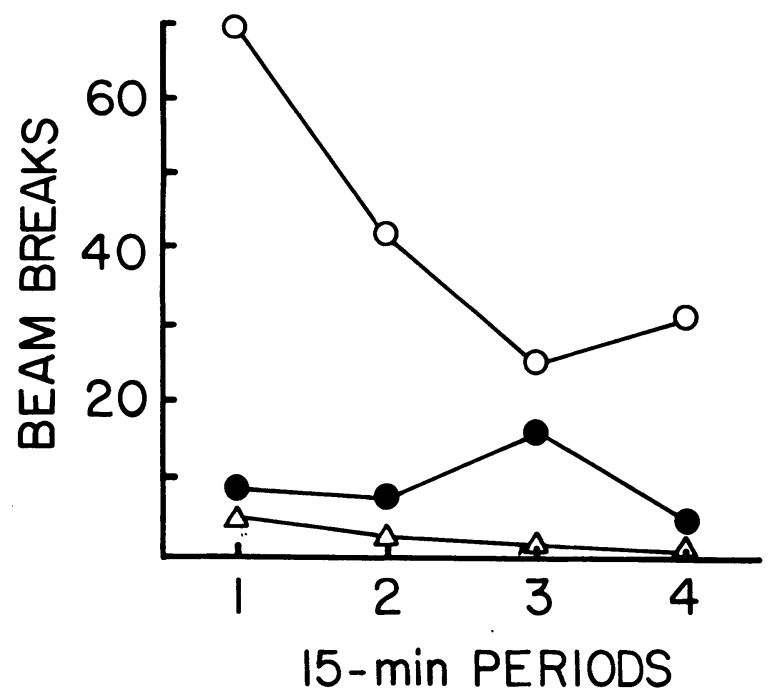

Figure 2. Effects of scopolamine on locomotor activity. Each point represents the mean number of photocell beam breaks in a 15-min period for four chickens. Open triangles: saline; filled circles: $.5 \mathrm{mg} / \mathrm{kg}$ scopolamine; open circles: $1.0 \mathrm{mg} / \mathrm{kg}$ scopolamine. guinea pigs and rabbits. How may we explain the significant findings by Thompson et al. and by Woodruff et al., as seemingly contradictory as they are? The procedures described in those studies, which involve the grouping of animals given like substances, might lead to inadvertant influencing of the results by the individuals inducing TI, if those individuals were aware of the injections given and of the design of the experiment. Gallup, Cummings, and Nash (1972) have previously reported that the behavior of the experimenter, once TI has been induced, may greatly influence the duration of tonic immobility. It also seems likely that if the experimenter did not expect TI to be induced, he or she might not carry out the induction procedure in the same way as if induction was expected to be successful. Thus, it would seem especially important in these studies, which include such an intimate involvement of the experimenter, that the experimenter be "blind" as to the experimental condition of each animal. One of the authors of the Thompson et al. study (Fallen, Note 1) has indicated in personal communication to the current author that the same individuals participated in injecting, marking, and testing the chickens in that study. The Woodruff et al. study does not mention steps taken to avoid this possible contamination. It may be that the significant results obtained in previous studies with scopolamine were due, not to the direct action of the drug, but to the expectation of the experimenters that the drug would be effective.

\section{REFERENCE NOTE}

1. Fallen, D. Personal communication, April 1973.

\section{REFERENCES}

Gallup, G. G., JR., Cummings, W. H., \& Nash, R. F. The experimenter as an independent variable in studies of animal hypnosis in chickens (Gallus gallus). Animal Behaviour, 1972, 20, 166-169.

KLEMM, W. R. Use of the immobility reflex ("animal hypnosis") in neuropharmacological studies. Pharmacology, Biochemistry and Behavior, 1976, 4, 85-94.

Maser, J. D., Gallup, G. G., JR., Hicks, L. E., \& Edson, P. H. Chlorpromazine dosage and duration of tonic immobility: Biphasic effects. Pharmacology, Biochemistry and Behavior, 1974, 2, 119-121.

Maser, J. D., Gallup, G. G., JR., \& Hicks, L. E. Tonic immobility in chickens: Possible involvement of monoamines. Journal of Comparative and Physiological Psychology, 1975, 89, 319-328.

Thompson, R. W., Piroch, J., Fallen, D., \& Hatton, D. A central cholinergic inhibitory system as a basis for tonic immobility (animal hypnosis) in chickens. Journal of Comparative and Physiological Psychology, 1974, 87, 507-512.

Woodruff, M. L., Hatton, D. C., Franki, M. B., \& Meyer, M. E. Effects of scopolamine and physostigmine on tonic immobility in ducks and guinea pigs. Physiological Psychology, 1976, 4, 198-200.

(Received for publication November 22, 1976; revision accepted August 15, 1978.) 